\title{
Picadura por Carabela Portuguesa, una "medusa" algo especial
}

\author{
Miriam Martínez Ramírez ${ }^{\mathrm{a}}$, María Emilia Villena Zálvez ${ }^{\mathrm{a}}$, \\ Inmaculada Marín Jara ${ }^{\text {, }}$, Josefina Monedero La Orden ${ }^{\text {b }}$
}

\begin{abstract}
a Residente de Medicina Familiar y Comunitaria. Centro de Salud Zona V-B, Albacete.

\section{${ }^{\mathrm{b}}$ Residente de Medicina} Familiar y Comunitaria. Centro de Salud Zona III, Albacete.

Correspondencia: Miriam Martínez Ramírez, Centro de Salud Zona V-B, $\mathrm{C} /$ Macedonio Jiménez s/n, 02006 - Albacete (España). Telf.: 627940905, e-mail: miriammar101@hotmail.com.

Recibido el 14 de mayo de 2010.

Aceptado para su publicación el 28 de mayo de 2010.
\end{abstract}

\section{RESUMEN}

La carabela portuguesa (Physalia physalis) es un hidrozoo que erróneamente se asocia con la familia de las medusas. Su picadura puede provocar intenso dolor, problemas respiratorios e incluso una parada cardiaca. La neurotoxina, secretada por sus tentáculos, tiene una alta toxicidad.

La carabela Portuguesa habita en aguas tropicales, pero, debido a la sobreexplotación pesquera y al cambio climático, este cnidario se avista cada vez con mayor frecuencia en costas del Cantábrico y el Mediterráneo.

El acercamiento de esta especie marina a las playas, las importantes lesiones que puede originar de forma inmediata y a largo plazo y el hecho de que su picadura puede ser motivo de consulta, incluso varios días después de producirse, hace interesante que sea conocida tanto por los profesionales que trabajan en zonas costeras como los que ejercen en zonas de interior.

Presentamos el caso de una mujer de 47 años con lesiones características de la picadura y describimos brevemente el diagnóstico y tratamiento.

Palabras clave. Venenos de Cnidarios, Mordeduras y Picaduras, Hidrozoos, Physalia Physalis.

\section{ABSTRACT}

Bite for Portuguese Caravel, a "jellyfish" something special.

The Portuguese caravel (Physalia physalis) is hidrozoo that erroneously is associated with the family of medusas. Its puncture can cause intense pain, respiratory problems and even a shutdown cardiac. The neurotoxin, secreted by its tentacles, has a high toxicity.

The Portuguese caravel lives in tropical waters; however, due to overfishing and climate change, this cnidarian is sighted with increasing frequency in the Cantabrian coast and the Mediterranean.

The approach of this species in sea beaches, major injuries can cause immediate and long term and the fact that their bite can be cause for consultation even several days after; for this reason, knowledge of this species is interesting for professionals who working in coastal areas such as those engaged in inland areas.

In this report, we present the case of a 47 year old woman with characteristic lesions of the bite, as well as a briefly describe the diagnosis and treatment.

Key words. Cnidarian Venoms, Bites and Stings, Hydrozoa, Physalia Physalis.

\section{INTRODUCCIÓN}

Physalia physalis, fragata portuguesa, carabela portuguesa, agua mala o botella azul es una cnidaria del género physalia, un tipo de hidrozoa de la subclase Siphonophora. Se suele encontrar en mar abierto en todas las aguas cálidas del planeta ${ }^{1}$, y en ocasiones es arrastrada a las playas.

La carabela, a diferencia de la medusa, es una colonia de pólipos flotantes, es decir, organismos coloniales, cada uno subespecializado para mantener viva la colonia. Se compone principalmente de una vela gelatinosa, que se encarga del desplazamiento al ser impulsada por el viento, y un cuerpo central con numerosos tentáculos con los que atrapa a sus presas. Estos tentáculos pueden llegar a medir más de 10 metros $^{2}$ (figura 1). 


\section{OBSERVACIONES CLÍNICAS}

Presentamos el caso de una mujer de 47 años sin antecedentes de interés que refiere dolor y prurito intenso en antebrazo, tobillo y muslo izquierdos tras haber sufrido una picadura de medusa hace diez días.

A la exploración observamos lesiones erosivas, exudativas y vesiculosas con disposición lineal "en latigazos" en antebrazo. En tobillo y muslo izquierdos presenta lesiones erosivas lineales de menor tamaño. El tratamiento recibido inicialmente fue lavado de la picadura con agua dulce y hielo local. Al día siguiente, debido a la persistencia de los síntomas, comenzó tratamiento con antihistamínicos orales (cetirizina $10 \mathrm{mg} / 24 \mathrm{~h}$ ) y analgésicos (paracetamol $1 \mathrm{~g} / 8 \mathrm{~h}$ ) sin notar mejoría y con empeoramiento de las lesiones, sobre todo la del antebrazo.

Una semana después, la paciente presenta intensa inflamación en antebrazo con una superficie tensa, brillante, enrojecida y caliente (figura 2). Ante la sospecha de celulitis se decide pautar cloxacilina 500 mg/6h, encontrando una rápida mejoría y quedando la lesión en fase de cicatrización.

La paciente vuelve a consultar a los tres meses por persistencia del queloide y aparición ocasional de eritema perilesional acompañado de leve prurito con el aumento de temperatura y al contacto con agua salada. Se realiza interconsulta al servicio de dermatología desde donde se recomienda una aplicación al día de rosa mosqueta en crema.

Ocho meses después de la picadura la paciente refiere que aún persiste el prurito ocasional con el agua salada y el aumento de temperatura. A la exploración encontramos mejoría de las lesiones, con reducción del queloide y sin eritema perilesional (figura 3).

\section{COMENTARIOS}

Aunque resulta imposible confirmar con certeza que la picadura fuera producida por una Physalia physalis sin la captura del cnidario, la paciente identificó la carabela portuguesa entre las imágenes presentadas de varios tipos de medusa. Esto, unido al hecho de que presentara otras lesiones bien distantes y parecidas a la principal y que la prensa local notificara la llegada de estas hidrozoas a las playas, nos permite confirmar el origen de la picadura con una probabilidad muy elevada.

Ante una picadura de medusa, es esencial preguntar cómo ocurrió, el tiempo transcurrido desde la picadura, los síntomas locales y sistémicos y la descripción del tipo de medusa².

Las lesiones producidas por el contacto local que nos podemos encontrar son edema, pápulas erite- matosas, ampollas, descamación, cambios isquémicos, neuropraxia, adenopatía regional y reacciones cutáneas a distancia ${ }^{1-6}$.

Excepcionalmente se produce afectación sistémica: cardiovascular (vasoespasmo, miopatía, insuficiencia cardiaca, arritmias, colapso cardiovascular), respiratoria (edema laríngeo, broncoespasmo, edema pulmonar, insuficiencia respiratoria), neurológica (parálisis espástica, cefalea, agitación, ataxia), gastrointestinal (náuseas, vómitos, necrosis hepática), renal (glomerulonefritis) y hematológica/inmunológica (reacción de hipersensibilidad) ${ }^{1,3,5,6}$.

También pueden producirse reacciones tardías y a largo plazo tales como: ulceración, celulitis, necrosis y gangrena. También estrías pigmentadas, queloides, liquenificación por rascado frecuente, granuloma, atrofia grasa o cicatrices. En el sitio original de la picadura, secundarias a respuestas inmunológicas intracutáneas, se pueden producir reacciones recurrentes sin que se repita la exposición inducidas por antígenos secuestrados ${ }^{1,3}$.

Se puede plantear el diagnóstico diferencial con las fitodermatitis, las fitofotodermatitis y las erupciones de los bañistas del mar. Esta última se caracteriza por la aparición de una erupción de pequeñas máculas y pápulas eritematosas, intensamente pruriginosas, en zonas cubiertas por el traje de baño. Aparece a las pocas horas de haberse bañado en el mar y se autolimita en unos 15 días. Parece ser debido a corales, algas o restos de medusas que quedan atrapados en la malla del bañador ${ }^{1}$.

El tratamiento de las picaduras de medusa consiste en lavar la región afectada con suero fisiológico o, en su defecto, con agua de mar. Nunca con agua dulce ya que facilita la absorción de la toxina. Se deben retirar con unas pinzas los restos de tentáculos que puedan quedar adheridos. No se debe frotar la zona afectada ni con arena ni con la toalla. La aplicación de hielo, puede aliviar, pero hay que tener la precaución de hacerlo con una bolsa de plástico para evitar el contacto con agua dulce ${ }^{1}$. Soluciones tópicas de bicarbonato de sodio y sobre todo de lidocaína parece que sirven para evitar la descarga de más toxina por las células (nematocistos) de sus tentáculos. Además, la lidocaína, al ser anestésico, nos puede ayudar a mejorar el control del dolor ${ }^{4}$. Aunque se ha defendido en algunas publicaciones el uso del vinagre en este tipo de picaduras ${ }^{6}$, se ha demostrado mediante microfotografía que la adición de esta sustancia al tentáculo de la Physalia physalis provoca una descarga del nematocisto, por lo que el uso de vinagre parece contraindicado. Ante la existencia de afectación sistémica, la prioridad es sacar al paciente del agua y asegurar vía aérea $(A)$, ventilación $(B)$ y circulación $(C)^{1-3,5,6}$. 
En nuestro caso, consideramos que el tratamiento inmediato de las lesiones probablemente no fue adecuado, ya que se debería haber usado agua salada, bicarbonato o lidocaína tópica en lugar de agua dulce.

La escasez de estudios sobre las reacciones tardías de las picaduras de medusas, y en especial de Physalia physalis, la dificultad para registrar estas lesiones y hacer un seguimiento óptimo y el aumento de avistamientos de estos particulares organismos en nuestras costas nos sugieren la necesidad de revisar este tipo de patología.

\section{AGRADECIMIENTOS}

A los Dres. Alejandro Villena Ferrer, Pedro Jesús Marín Cabezuelo y Salima Qudsi Sinclair por la colaboración y dedicación prestada en la elaboración del artículo.

\section{BIBLIOGRAFÍA}

1. Vera C, Kolbach M, Zegpi MS, Vera F, Lonza JP. Picaduras de medusas: actualización. Rev Méd Chile. 2004; 132:233-41.

2. Nimorakiotakis $B$, Winkel KD. Marine envenomations. Part 1--Jellyfish Aust Fam Physician. 2003; 32(12):969-74.

3. Burnett JW. Treatment of Atlantic cnidarian envenomations. Toxicon. 2009; 54(8):1201-5.

4. Birsa LM, Verity PG, Lee RF. Evaluation of the effects of various chemicals on discharge of and pain caused by jellyfish nematocysts. Comp Biochem Physiol C Toxicol Pharmacol. 2010; 151(4):426-30.

5. Kaufman MB. Portuguese man-of-war envenomation. Pediatr Emerg Care. 1992; 8(1):27-8.

6. Auerbach PS, Norris RL. Trastornos producidos por mordeduras de serpiente y por venenos de animales marinos. En: Fauci AS, Braunwald E, Kasper DL, Hauser SL, Longo DL, Jameson JL, et al, editors. Harrison Principios de Medicina Interna 17. Méjico: McGraw-Hill/Interamericana; 2008. p. $2741-48$.

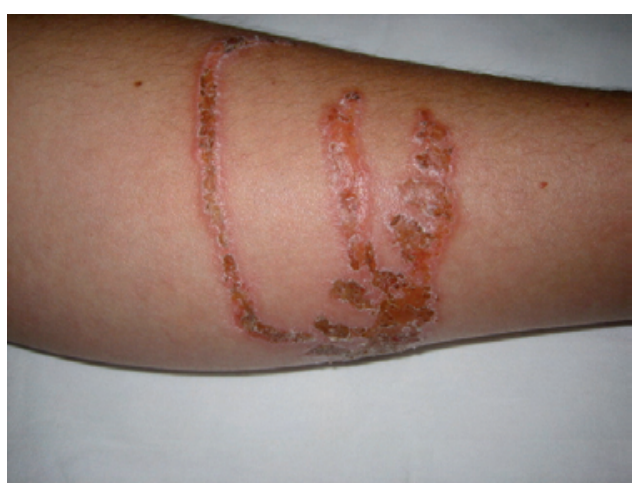

Figura 2. Lesiones por picadura de Physalia Physalis de 10 días de evolución.

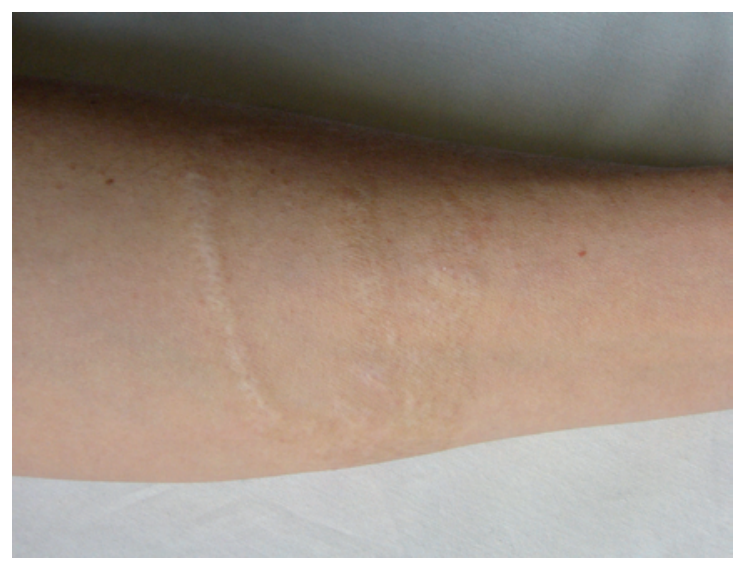

Figura 3. Lesiones por picadura de Physalia Physalis de 8 meses de evolución. 